Journal of Computer Science 4 (5): 382-392, 2008

ISSN 1549-3636

(C) 2008 Science Publications

\title{
The Complexity Paradigm: Implications for Information Systems and their Strategic Planning
}

\author{
Indranil Mukherjee \\ School of Management, West Bengal University of Technology, \\ BF 142, Salt Lake, Sector I, Kolkata-700064, India
}

\begin{abstract}
The complexity framework was employed to analyse Information Systems and the strategic planning process associated with them. We provided an overview of the theories of complexity and their significance. The salient features of strategic planning for information systems were discussed and the need for a new paradigm, viz. complexity was pointed out. The concept of Class of a Complex System was introduced and a model for analysing complexity was given. The implications of the complexity model in the context of strategic planning were considered and a few actions, which draw upon the Complex Adaptive Systems (CAS) approach, were suggested for information system planners.
\end{abstract}

Key words: Complexity, classes of complex systems, information systems, strategic planning

\section{INTRODUCTION}

The importance of Information Systems (IS) in adding value to a corporate organization is now a wellestablished fact. Information systems have evolved from being synonymous with corporate data processing and back-room operations supporting routine tasks, to work systems, which are of strategic importance to organizations $s^{[1,2,3]}$. They are endowing competitive advantage to organizations in different ways, e.g., by changing the industry structure, arming companies with newer techniques to outwit their rivals and sometimes by throwing up entirely new business models from within a company's existing operations ${ }^{[4]}$. With the success of information systems becoming crucial to the sustainability of organizations, Strategic Planning for Information Systems (SP4IS) is fast emerging as a critical issue. In several industry surveys, SP4IS is being mentioned as the most serious challenge facing IS managers ${ }^{[5,6]}$.

The reasons responsible for the formulation of a strategic plan for an information system may be different in the case of different organizations, but the purpose of all such plans is fundamentally the same. The objectives of such a plan are broadly the following ${ }^{[7]}$ :

- Managing an expensive and critical asset of the organization in an effective manner

- Aligning the information systems direction to the business direction
- Planning the flow of information and processes

- Allocating information system resources effectively as well as efficiently

- Reducing the time and expense of the information systems life cycle

Development of any Computer Based Information System (CBIS) is always in response to a set of needs of the organization where the system is getting installed. Hence, strategic planning for information systems begins by identifying the needs of the company, whether at the level of transaction processing or at the more complex information and support system levels. The plan attempts to identify specific projects designed for the future, priorities for each project and for resources, constraints for each application area etc. The plan should be specific enough to analyse each application and point out its priority, but must possess sufficient flexibility to allow for the adjustment of priorities, if at all necessary. It must analyse a company's information and processes using business information models along with the evaluation of risk, current needs and requirements. SP4IS thus turns out to be a management function, having the objective of aiding the organization in executing its business plans and achieving its business goals. This corroborates the status of such planning as the application of information technology to a firm's strategic initiatives aiming to maximize its business returns ${ }^{[8]}$.

Corresponding Author: Indranil Mukherjee, School of Management, West Bengal University of Technology, Kolkata-700064, India 
There appears to be little research that explicitly addresses the specific factors affecting success with strategic planning for information systems. It is necessary to examine the issues by considering the full range of factors across the complete application life cycle. The objectives of the present research are twofold:

- To develop a framework for understanding the issues affecting the degree of success with strategic planning for information systems

- To identify those particular factors which might be crucial in determining the success of such a plan and understand how these factors might have elements of complexity embedded in them

It is generally true that success of a strategic plan (and its implementation) goes far beyond merely considering the technical aspects detailed therein. This has motivated researchers to transcend the mere technological explanations of success and failure and move to a rich and complex analysis of human organizational systems ${ }^{[9,10,11]}$.

The theories of complexity become important precisely at this point, where there is a need to integrate technical and social factors in order to analyse and evaluate strategic planning for information systems. Complexity is proving to be the ultimate of interdisciplinary fields covering different areas of natural and social sciences, as well as the entire spectrum of management and allied disciplines $^{[12,13,14,15,16]}$. There is probably no single theory of complexity. A number of approaches exist arising out of the different disciplines that cover this multifaceted field. Depending on the particular discipline, the specific problem addressed and the individual researcher's background, the complexity approach has been characterized as constituting everything from a major paradigm shift which challenges established scientific orthodoxy to an extension and refinement of existing theory ${ }^{[17]}$.

The present study attempts to study Information Systems and their Strategic Planning in the framework of complexity theory. Research work, which treats information systems from the complexity perspective are currently few but are gradually beginning to appear ${ }^{[18,19,20]}$. Complexity probably provides the most appropriate structure for analysing IS and their strategic planning. This paper is primarily an exercise in exploring the concepts and ideas of complexity in the area of IS and has little to do with field research. The paper will pick up some of the prominent features of complexity and Complex Adaptive Systems (CAS) and try to correlate these features with the key concepts prevalent in SP4IS.

\section{OVERVIEW OF STRATEGIC PLANNING FOR INFORMATION SYSTEMS}

The information system planning process has the same basic components as a business planning process, viz.

- Identification of the present situation - this includes looking internally and externally at the business as well as the information system

- Identification of the target situation - this should be from a business perspective as well as an information system perspective, the future business direction being the main determinant in the information system direction

- Identification of the information system gap between the current and the future situations

- Identification of how to take the information system to the desired state, viz. developing a plan

These different components are shown in Fig. $1^{[21]}$. SP4IS tries to close the strategic gap that may exist between the potential opportunities which IT can provide and the actual ability of the organization to identify, utilize and implement IT solutions that can take advantage of these opportunities. The principal aims of such a planning process are: (a) to align and focus the IS and IT strategies of the organization so as to best support and reinforce the business mission and goals; (b) to link the business, systems and IT planning cycles in order to ensure continuing focus on strategic priorities; (c) to secure and retain top management commitment to the planning process and to facilitating the implementation of that process; (d) to identify and exploit opportunities offered by IT so that the organization can gain and hold a competitive advantage. It may be mentioned that the basic block diagram (Fig.1) remains unchanged even when complexity is taken into account, but both strategy formulation and strategy implementation undergo certain modifications, particularly the latter. Organizations need to initiate suitable actions to streamline their strategic planning process in the light of complexity.

The strategic planning process commences with understanding the future business operating vision. The business operating vision functions as the basis for the information system mission, objectives, strategies and technical computing architecture. The current systems are reviewed by comparing them to the projected 


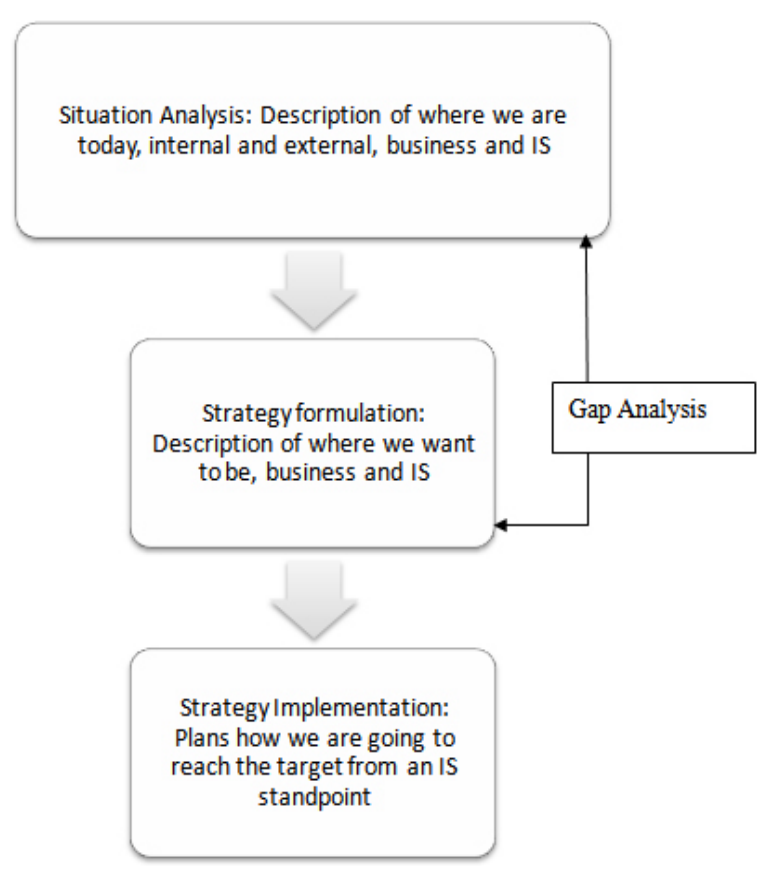

Fig. 1: Plan components

business vision and the preferred information system architecture. The end products of this exercise are a set of plans which are manifestly necessary to the business, are understandable, manageable and maintainable. The entire process is depicted in Fig. 2.

It is worth mentioning here that the basic structure shown in Fig. 2 remains invariant even under the microscope of complexity, but the IS strategies need to be revised suitably.

SP4IS also has an important place in the software development life cycle. This is particularly useful as it portrays the connection between the planning process at the strategic level and the lifecycle model, which is at the heart of any information system development process.

There is, however, one important difference between SP4IS and the more traditional methodologies, which are practised in the discipline of information systems. Unlike the procedures followed for the design and implementation of information systems, methods for the formulation of IS/IT strategic plan cannot be entirely prescriptive. This is probably because these methods draw heavily on business logic and are dependent on several management issues and practices. Variations encountered in business style and management practices often call for a significant amount of customisation in the planning process.

In addition, the strategic planning process sometimes suffers from some other defects which could

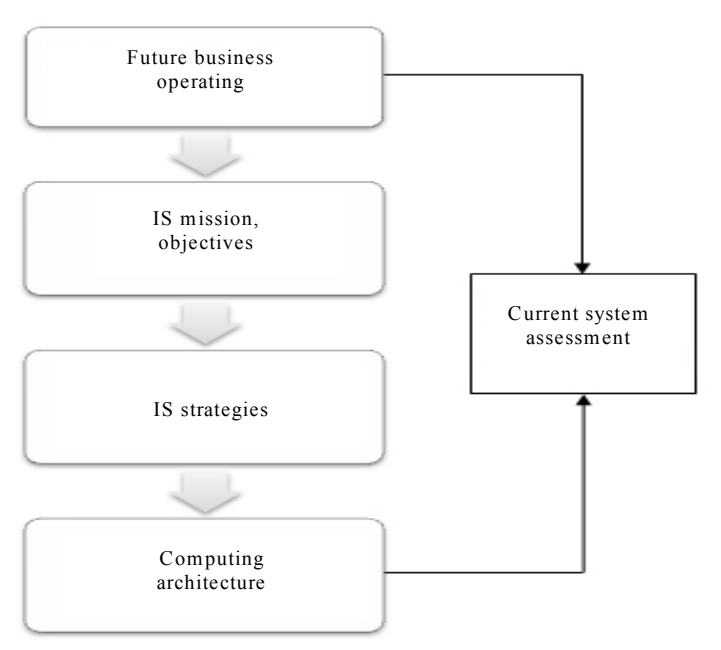

Figure 2: Plan Development

be detrimental for an organization. Some of these are inherent in the planning process itself and may not be easy to avoid. Mention may be made of the following:

- A failure to isolate unpredictable issues from regular or predictable ones while designing the strategic plan. Unpredictable or temporary issues often arise which are genuinely strategic in their importance, but which are not well suited to resolution through a standard planning procedure

- A conflation of business units and corporate strategy issues while devising the plan. This often tends to undermine the planning process to a business review exercise, which often pits the corporation function against line management by reducing the planning activity to one of strategic auditing

- Isolation from the line - the process employed is often too time intensive for senior information system project managers to participate in, leading to the process being viewed as inefficient or merely an academic exercise

- A failure to link the strategic plan to explicit measures of corporate success and associated tracking systems. In that case, the planning process stands isolated, with no clear linkage to specific events in the business. No early warning systems exist to indicate major departures from expected or desired outcomes

The lacunae present in the strategic planning process has been perceived to be one of the factors responsible 
for the abject failure of some information systems which were developed after devoting a great deal of time and effort to the entire process. Some of the examples are the London Ambulance Service case study ${ }^{[22]}$, the New York City AT\&T case ${ }^{[23]}$, the Confirm reservation system ${ }^{[24]}$, the Bank of America trust system etc. All these systems lacked the characteristics of the idealized low-risk project. They were complex from both technical and organizational viewpoints. They required inputs from many stakeholders in business situations in which new information and new priorities were emerging continuously.

The situation becomes far more challenging in the process of creating effective information systems to support decision-making and group processes, to provide an organizational backbone and to support information flow within an organization. A multitude of factors need to be considered while devising a strategic plan for information systems. Theories of chaos and complexity are suitable tools for helping to devise effective strategic plans for information systems. They can be used to identify the factors, which when considered and included in the strategic plan, would lead to a successful implementation of the desired information system.

\section{THEORIES OF COMPLEXITY AND COMPLEX ADAPTIVE SYSTEMS}

The concept of complex systems has already been introduced. However, it is difficult to give a rigorous definition of complexity or complex systems because the notion of a complex system is not yet precisely delineated. It is probably easier to convey the meaning of complexity by enumerating some typical properties of complex systems ${ }^{[25]}$.

Complex systems contain many constituents interacting nonlinearly. The constituents of a complex system are interdependent. The complexity of the system does not arise from complex rules, but rather from the interaction among the large number of entities or subsystems that the entire system is composed of. Simple rules and simple initial conditions can give rise to the most computationally complex behaviour (in a rigorous and formal sense).

A complex system possesses a structure spanning several scales. Consider the case of a government, which is an example of a complex system. There are different levels (scales) in the government: local (city corporations or municipalities), state and the union government. At every scale there is a structure present.
This is an essential and radically new aspect of a complex system.

A complex system is capable of emergent behaviour. Emergence occurs when we switch the focus of our attention from one scale to the coarser scale above it. A certain behaviour, observed at a certain scale, is said to be emergent if it cannot be understood when we study, separately and one by one, every constituent of this scale, each of which may also be a complex system made up of finer scales. Rather, the emerging behaviour is a new phenomenon special to the scale considered and it arises from the global interactions between the scale's constituents. In other words, it is hard to predict the emergence of the global property from the knowledge of the component parts. This global property - the emergent behaviour - feeds back to influence the behaviour of the individual components that produced it. For example, in industrial societies, the aggregate behaviour of companies, consumers and financial markets produces the modern capitalist economy. For the brain, billions of neurons interact to yield complex behavioural patterns.

The combination of structure and emergence leads to self-organization, which is the outcome when an emerging behaviour has the effect of changing the structure or creating a new structure. Each higher level has its own scale and each new level has new kinds of relationships and properties. This means that a complex system at one level is made up of lower level complex systems interacting and creating the higher-level order. Self-organization is not a strictly nested phenomenon; complex webs of interactions may exist at all levels.

There is no single point of control in a complex system. Complex systems show global coordinated behaviour, without the presence of any distinct global controller. A complex system must cultivate variety, but it is an illusion to think that one can direct the variations. One can only disturb the system and observe what is happening. At the same time one cannot be separate from the system, stand outside and influence its direction. For example, neither has the immune system got any chief lymphocyte which directs an immune response; nor does the brain have a chief neuron in which central control of all behaviour is located.

There is another property of complex systems worth discussing. This is a property characteristic of all social systems like ecological groupings, immune systems, social or economic classes, teams, dotcom ventures, nations and supranational corporations. In all these organizations, complexity involves interplay between cooperation and competition. Examples abound in the fields of economics and social sciences. 
There is a special category of complex systems known as Complex Adaptive Systems ${ }^{[26]}$. As the name signifies, these systems are capable of changing themselves to adapt to a changing environment. They can also change the environment to suit themselves. A formal definition runs as follows: A Complex Adaptive System (CAS) denotes an open ended system of many heterogeneous agents which interact nonlinearly over time with each other and their environment and which are capable of adapting their behaviour based on experience. Open ended means that there is essentially limitless possibility for variability in agent characteristics and behaviour. Typical examples include ant colonies, immune systems, brain, markets and companies.

An interesting example of the remarkable power of complexity theory concerns the growth and flourishing of the Silicon Valley, the nucleus of intellectual activity in the software industry of the United States ${ }^{[27]}$. Selforganization in the Silicon Valley occurred in two ways: (a) University scientists, entrepreneurs and investors continuously self-organized to form start-up companies; (b) corporations, academic institutions and venture capital firms self-organized to form strategic alliances, partnerships and temporary project teams. Silicon Valley also combined the ingredients of emergence: sparks of innovation (mainly coming from Stanford University and UC at Berkeley), technology, capital, heterogeneity (intellectual and ethnic) and an overall upbeat atmosphere. Genetic mixing within the Valley was boosted by constant employee turnover. Serial employment being the norm in the Silicon Valley, firms competed intensely; at the same time, they cooperated, learnt from and partnered with one another.

\section{STRATEGIC PLANNING UNDER COMPLEXITY}

The principal aim of strategic planning is to steer an organization by evaluating present procedures and exploring future objectives in the light of a mission ${ }^{[28]}$. In order to analyze strategic planning under the microscope of complexity, it is necessary to understand foresight horizons, i.e. how far ahead the strategist can foresee events. Foresight horizons can be clear, complicated or complex ${ }^{[29]}$.

For a clear foresight horizon, the strategist is able to envision the different types of scenarios which may arise from a given situation, knows the factors which would be decisive in that setting and the terminal date for the uncertainty in the given situation. The method of decision analysis is applied for the purpose of strategic planning in this case.
In the case of complicated foresight horizons, the strategist would be aware of the different kinds of situations that might arise, but because of the sheer number of possible combinations it is very hard to visualize all of them at the outset of his journey. However, the strategist believes that he would be able to learn about the crucial eventualities in a timely manner so as to respond efficiently to different situations. Thus, the unimaginably large number of possible outcomes and the difficulty of assessing probabilities, let alone assigning values, forces strategic planning to become the organization of processes of continuous experimentation, exploration and subsequently adaptation.

In complex foresight horizons, the problem of the strategist is not only to negotiate his way through a fixed landscape composed of familiar, if presently unknown factors. Rather, the social landscape through which he moves constantly deforms in response to the action he and others take and new features, not previously envisioned or perhaps envisionable, emerge. As the destination of the strategist is always temporally beyond his current foresight horizon, the connection between what he does and where he is going is always tenuous and therefore ambiguous. In the case of organizations, this calls for efforts to foster selforganization and co-evolution through such techniques as learning circles, peer learning groups, systems thinking etc. There may not be a predictable future but there is a need to engage in futuring continually constructing a future. The emphasis on learning organizations along with the need to construct a future leads to such planning concerns as:

- How can we be clear about our purpose and values and use them to structure modes of communication that support interconnectedness among the various stakeholders?

- How can we optimise and construct relationships in organizations so as to foster complexity, selforganization and futuring?

- How can we encourage resiliency in the organization so as to make complex, reliable decisions in the presence of a large number of often-conflicting inputs as we co-evolve between order and chaos?

It is necessary to invoke the ideas of complexity in order to answer one or more of the above questions because the questions themselves arise from the complexity framework. The concept of complex foresight horizons makes this quite evident. 
While studying the development of Information Systems in organizations it is useful to remember that organizations are dynamical systems in a constant state of flux. Their inherent fluidity often makes it difficult to identify user requirements in a precise manner. The dynamicity of the working environment ensures that a gap between information systems and user requirements appears much before implementation is finished and that there is a constant co-evolution of the two processes. IS development lead times are shortening, but it is difficult to overcome the time related problems, by reducing the gap between problem definition and solution realization. The only answer is to make the Information Systems more flexible and adaptive, i.e. model them as Complex Adaptive Systems. The IS strategist, therefore, needs to have a complex foresight horizon.

It is also interesting to observe that the time evolution of an organization - a complex system - is characterized by changing, non-repetitive patterns. These patterns progress non-linearly - periods of inactivity are followed by sudden changes, followed by periods of stability once again (punctuated equilibrium). An organization does not necessarily progress linearly in a stepwise manner towards a predetermined goal of maturity. For example, a mistake committed during a particular IS development effort may get repeated in new and original ways. Lessons learnt from previous development experiences may not really prove to be of any value. A chaos/complexity view suggests that recording of these lessons in terms of standards and best practices would not necessarily guarantee future success since the unexpected could occur, new patterns emerge and intentional practice lead to unintended as well as unexpected effects. Small and apparently insignificant events, whether technical or managerial, sometimes can have a striking effect on the development of IT within an organization-the so called butterfly effect. An interesting example would be one where the decision to commit to a particular type of technology had surprisingly large effects at a later time when a change in IT platform was considered and found to be impracticable.

It is fairly obvious that the chaotic patterns of organizational behaviour ingrained in the development, adoption and management of information systems, can hardly be studied by collecting information at a single point in time. The interactions of actors within an organization and their effects on information systems is best illustrated by narrative studies which describe patterns of behaviour in which paths of influence can be traced.
All these facts have important implications in the analysis and design of information systems and in the context of undertaking strategic planning for such systems.

Protagonists of complexity theory argue that strategic planning for information systems would suffer greatly if there is overemphasis on extrapolative planning process culminating in freezing of strategic planning systems into oversimplified, linear checklist and lock-step approaches. They advance the idea ${ }^{[30]}$ that instead of choosing singularly focused strategies, organizations need to explore multiple strategies, some of which would operate in parallel, in order to encourage co-evolution. The different such strategies should aim to deepen and extend current practices, create new practices and sow the seeds for future developments. Cultivating multiple strategies in planning for information systems, implies less rigidity in thinking, that is, greater flexibility in the grip of unexpected situations - this is extremely important, as long term planning is illusory in chaotic environments.

\section{A MODEL FOR ANALYZING COMPLEXITY - CLASS OF A COMPLEX SYSTEM}

In this study, we introduce a simple model for studying a complex system ${ }^{[26]}$. This model consists of the following elements:

1. Agent: An element which has the ability to interact with its environment, including other elements, e.g., a person, a family, a business, a country or an environment. In the context of an information system and its strategic planning, the factors which are significant in determining the relative success of these, can be termed as agents. From the population of agents, we can determine types-a type being a category of agents that share some detectable combination of features. A set of agents shall be categorized as belonging to one particular type. This categorization might be in terms of the information systems development methodology that we adopt, e.g. the waterfall model.

2. Variety: A fundamental assumption of Complex Adaptive Systems is that no two agents are inherently the same. The variety within a population is a central requirement for adaptation and leads to the rich dynamics present in complex systems. The different variation mechanisms which operate among the agents are the following:

Copying: This is the most primitive birth process. When it functions without error, the result is an increase 
in the frequency of one of the population types. Mutation is a copying error which increases the variety by creating new types and altering the relative frequency of the different types.

Endogenous copying mechanisms: These are triggered by events internal to the system in which they operate and produce new types or changes in type frequencies in a more targeted and less random fashion. Selection is the most prominent example that creates copies of some agents or strategies from a population and eliminates copies of others. With passage of time, selection reduces the variety of types in a finite system, though in the beginning it may increase the relative frequencies of some rare types. If the selection among types favours more common types, then a type with a slight edge in frequency over the others can grow quickly to become predominant in the population. The conventional example of this dynamics is the competition between the QWERTY and Devorak keyboard arrangements.

Recombining mechanisms: These help to create new types. Examples are crossover/conceptual recombinations (splicing together already existing agents) and constraint relaxation (seeking solution to a hard problem by generating variants that violate some of the situational constraints, it introduces new variants by starting with materials of established feasibility and modifying them).

Exploration versus exploitation: This is an important trade-off principle, which plays a vital role in the selection of suitable agents/strategies. This involves creation of untested types that may be superior to the one which currently exists (exploration) versus the copying of tested types that have so far proven best (exploitation). This type of trade-off occurs across a wide spectrum of settings, from genetics to organizational resource allocation, wherever the testing of new types comes at some expense to realizing benefits of those already available. A practical example might be for a company to decide on whether to invest resources for developing an entirely new information system or to update and streamline the existing information system.

An instructive example of the conditions that favour encouraging variety may be provided from the field of information systems. This is the case of the Linux Operating System and the method employed to organize the work of its development team ${ }^{[31]}$. This method is known as open source software development and involves the free availability of the source code.
Although Linux is given away free by its developers, it has become particularly useful in situations which demand high reliability. Many of the features characteristic of Linux can be explained by considering the development of Linux as a Complex Adaptive System. For example, free access to the source code of Linux allows programmers to effect changes, creating a new version of the program. From a CAS viewpoint, the possibility for volunteers to create working variants increases significantly the variety of the population of operating systems. This variety can then be harnessed to yield a robust and stable operating system. The structural arrangements pertaining to the development of Linux are planned in such a way that exploration becomes truly beneficial. The instance of a programmer modifying the source code of Linux is an example of endogenously triggered recombination. The trigger for this activity is generally an observed lacuna in the performance of the existing standard version of the operating system. The affected user usually seeks help from the large community of Linux programmers. There are responses from interested individuals about fixing the bugs. These small pieces of new code are recombined with the remaining part of the standard version to generate new variant versions. Following a period of testing and performance evaluation, the bestperforming variant is accepted by the small team of key Linux developers and the new code gets incorporated into a subsequent standard version of Linux. The bottomline is that the variety emanating from the free availability of the source code can be put to effective use to produce a rapid improvement in the overall quality of the code. Thus development of Linux is a very important test case where encouraging variety within the system turns out to be extremely productive. Although several other factors contributed to the success of this project, yet the fact remains that adopting the principles of complexity in the form of promoting variety played a significant role in the success of Linux. By the process of extrapolation, one can argue that the principle can be adopted profitably for the development and strategic planning of other types of information systems as well.

3. Interaction: Once the sources and nature of different types of variation among agents are identified, it is necessary to explore the different patterns of interaction taking place within and among agents and types. The study of interaction is essential for understanding the behaviour of complex systems because the events of interest within a system arise from the interactions of its agents with each other and with artefacts. 
Interactions make a Complex Adaptive System (CAS) come alive. The system becomes not a mere pile of agents of varying types but a population that gives rise to events and has an unfolding history

Interactions among agents and types are actually the different forces/patterns that favour the occurrence of certain events and dampen some others, depending on the mutual feedback. This is actually the concept of the feedback loop. A chain of interactions should be traced (i.e. which action generates what response) that allows the feedback loop concept to be established.

There are two types of factors which control the various patterns of interaction. Proximity factors determine how agents are likely to interact with one another. Activation factors determine the sequencing of their activity. This distinction broadly generalizes that between space and time.

The mechanisms dealing with interactions can also be broadly divided into two classes: external and internal. The external mechanisms are methods to modify the system from outside e.g. by designing artefacts, or by policy making that changes the rules others play by. The internal mechanisms are ways to change the interaction patterns that are driven by processes occurring within the system.

In the light of the preceding discussions, it is apparent that one should try to identify the different variation mechanisms and interaction patterns that can influence the different agents and types involved in a strategic information system plan. Armed with such knowledge, organizations can devise their information system strategies in such a way as to minimize the chance of getting affected unexpectedly by forces of complexity. To do this, it is necessary to introduce the concept of Class of a Complex System ${ }^{[32]}$. It is then possible to understand the implications of this concept for the information system strategic planning process.

There are four classes of behaviour in any Complex Adaptive System, viz. Class I, Class II, Class III and Class IV models (systems). In Class I type of models, any and every combination of the different agents and types quickly approaches a steady equilibrium state where all agents are dead. Thus, life is extinguished, i.e. no agent or type stands any further chance of influencing the system. In Class II type of models, the agents develop into static groupings or patterns of live agents, or perhaps groups of cells that oscillate between fixed states. Class III models are the opposite of Class I and Class II models. Class III models are chaotic - the cells alternate wildly between on and off positions and there are no predictable patterns or stability.
Class IV models are a combination of Class II and Class III, “......coherent structures that propagated, grew, split apart and recombined in a wonderfully complex way"[33]. Class IV models are capable of producing extended transients: Structures that can survive and propagate for an arbitrarily long time. To a greater or lesser extent the behaviour of these extended transients is stable and predictable. However, there is also a degree of uncertainty in Class IV systems and extended transients may be destroyed by an interaction with another entity or completely random mutation. This classification is exactly in conformity with the four types of behaviour roughly displayed by complex systems, viz. (i) steady state (Class I); (ii) periodic (Class II); (iii) chaotic (Class III); (iv) complex (Class IV).

\section{IMPLICATIONS OF THE COMPLEXITY MODEL FOR STRATEGIC PLANNING}

The following factors need to be considered while devising the strategic plan for an information system, viz. planning factors, evaluation factors, implementation factors and benefit realization factors. In the language of the complexity model, these are different types of agents, each of which is unique in nature. To help in the strategic planning exercise, one needs to identify the different variation mechanisms that operate within and among the different types of agents. One should also study the different modes of interaction operating within the system. In a Complex Adaptive System, the agents are interconnected through commonly held criteria for making decisions (operating values) and a shared purpose that also indicate the way they relate to each other and to the stakeholders. Thus a CAS approach to Strategic Planning for Information Systems (SP4IS) would be an opportunity to reconstruct relationships and construct possibilities through dialogue and networking among both internal and external groups. This calls for analysing the process of strategic planning from the perspective of Class of a Complex System.

Strategic planning in a Class I system is a trivial exercise as the behaviour tends towards death. It is also a relatively simple case in Class II systems since the behaviour of these systems is both stable and predictable. Planning is based on identifying repetitive historical patterns and projecting them into the future. The process may, however, be complicated by the presence of measurement error or complex business cycles.

Class III or chaotic systems display a sensitive dependence on initial conditions. This makes accurate 
predictions of future conditions virtually impossible. Hence long term strategic planning is simply not possible in Class III systems beyond specifying the broad limits of the behaviour of interest, e.g. an information system, properly designed and implemented, is likely to increase the efficiency of an organization.

Systems of the Class IV type are especially interesting. If it is assumed that extended transients in such systems display regular behaviour over prolonged time periods, it would appear that strategic planning is indeed possible in Class IV systems. But planners for a Class IV system need to show more caution in their approach. At any point of time, an unforeseen interaction with a chaotic element or any other transient in the system has the potential to divert or destroy the elements of the extended transient - this is the property of punctuated equilibrium coming into play. With increase in turbulence, Class IV complexity systems will move away from a resemblance to Class II stable systems and tend towards the characteristics of a Class III chaotic system. Organizations should then direct resources away from trying to predict the future state of the system and move towards learning new adaptive behaviour. But, to the extent that there are islands of stability in the system, strategic planning will still be worth doing.

There is evidence to support the view that the business world is a complex system poised on the edge of chaos. Industries appear to go through long periods of incremental change with the occasional discontinuity or punctuated equilibrium ${ }^{[34,35]}$. There are, in fact, several examples of companies that have dominated their respective industries for several years. IBM, Microsoft and Sun Microsystems are prominent examples from the IT industry. These facts suggest that business systems tend to follow a power-law distribution indicative of a Class IV system. Of course, these systems can experience a sharp increase in turbulence during rare periods. The system might even turn chaotic for a brief period of time before being pulled back to the edge of chaos.

The fact that relatively stable conditions may prevail for protracted periods of time indicates the efficacy of strategic planning in these situations. This is particularly interesting in the context of the IT industry and generally for information systems developed in organizations. This is because, information technology is a rapidly evolving discipline and the needs of information systems are also changing constantly. While formulating a strategic plan when developing information systems, one can consider the following actions all of which rely on the Complex Adaptive System (CAS) framework :

\section{Variation:}

- Organizational routines should be drawn up in such a way that a proper balance between exploration and exploitation is achieved, e.g. there is a need to strike the right balance between developing entirely new Information Systems and updating/refining the already existing ones.

- The processes that generate extreme variation should be linked to processes that select with few mistakes in the attribution of credit. We can again cite the example of the Linux OS, where it was possible to use the Internet to increase the variety of proposed improvements to the operating system. Such variation did not harm the integrity of the software, because the programmers involved in the exercise all agreed to follow certain specified performance criteria like speed of execution and robustness of the modified software.

- The general conclusion is that there should only be requisite amount of variation in the strategy - it is necessary to understand which agents should be copied and which should be destroyed, so as to reduce the potential threat of complex intervention.

\section{Interaction:}

- Organizations should strive to build networks of reciprocal interaction that promote trust and cooperation. It then becomes far easier to sustain the pace of the strategic initiative and implement the strategic plan.

- Strategies should be assessed after carefully considering what their consequences will be. The strategic plan then becomes a much more effective tool in developing an information system which would be value-maximizing for the organization.

- Organizations should avoid getting mixed up in possible large-scale failures while pursuing shortterm benefits. Significant risks can result from efforts to increase local efficiencies by linking processes that were not previously connected. For example, an information system may be planned where excess load can be shifted among linked computing systems, but if and when the bigger system collapses, the results can be absolutely catastrophic. A strategic plan, drawn up meticulously, with good design features incorporated, can always minimize the risks, but the risks should not be overlooked. 
In summary, organizations considered as Complex Adaptive Systems should try to judge which agent should interact with what other agent and when, so as to optimize the evolution of new agents in benefit of the organization.

\section{CONCLUSION}

A Complex Adaptive Systems (CAS) approach to Strategic Planning for Information Systems (SP4IS) emphasizes mindfulness, promotes mission and value based decisions, encourages fostering of relationships and systems of communication and tries to build possibilities that add to an organization's selforganization and resilience in its immediate and distant environment. In the event of sudden or unexpected changes, organizations need to abandon strategic planning in favour of organizational learning where the firm needs to adapt to its changing environment. Adaptation also leads to incorporating some variation and interaction mechanisms in the system. Strategic Planning will continue to have a positive pay-off in the development of an Information System as long as regions of stability remain within the system.

\section{REFERENCES}

1. Alter, S., 2004. Information Systems: The Foundation of E-Business. 4th Edn., Pearson Education, pp: 1-30. http://www.stevenalter.com/ work $2 . h t m$

2. Laudon, K.C. and J.P. Laudon, 2007 Management Information Systems, 8th Edn., Pearson Education, pp 1-25. http://www.prenhall.com/laudon

3. Avgerou, C. and T. Cornford, 1998. Developing Information Systems: Concepts, Issues and Practice. 2nd Edn., London, MacMillan. http://www.amazon.co.uk/Developing-informationSystems-Concepts-Macmillan/dp/0333732316

4. Porter, M.E. and V.E Millar, 1985. How Information gives you Competitive Advantage; Harvard Business Review. July-August, 2-13. http://www.hbsp.harvard.edu/hbsp/hbr/arti cles/article.jsp?articleID $=85415 \& \mathrm{ml}$ actio $\underline{\mathrm{n}=\text { get-article\& }}$ print $=$ true

5. Pant, S. and C. Hsu, 1995. Strategic information systems planning. A Review Proceedings of the 1995 Information Resources Management Association International Conference, May 21-24, 1995, Atlanta, Georgia, USA; IDEA Group Publishing, pp: 228-230. viu.eng.rpi.edu/ publications/strpaper.pdf
6. Parvi, F., and J. Ang, 1995. A study of the strategic planning practices in Singapore. Inform. Manage., 28: $33-47$. doi : $10.1016 / 0378-$ 7206(94)00027-G

7. Ward, J. and J. Peppard, 2002. Strategic Planning for Information Systems; 3rd Edn., John Wiley and Sons, 2002, US. www.amazon.co.uk/StrategicPlanning-Information-SystemsWiley/dp/0470841478

8. Earl, M.J., 1993. Approaches to strategic information systems planning: experience in 21 UK organizations. MIS Q., 17: 1-24. http://WwW. jstor.org/pss/249507

9. Flowers, S., 1994. Software Failures Management Failures: Amazing Stories and Cautionary Tales. Chichester, UK: John Wiley and Sons. http://portal.acm.org/citation.cfm?id=2611 $87 \& \mathrm{dl}=$ GUIDE\&coll $=$ GUIDE\&CFID $=35$ 645103\&CFTOKEN $=76715376 \quad$ ISBN:0471-95113-7.

10. Davis, G.B, Lee, A.S, Nickles, K.R, Chatterjee, S. Hartung, R and Y. Wu, 1992. Diagnosis of an Information Systems Failure. A Framework and Interpretive Process. Inform. Manage., 23: 293318. www.misq.org/discovery/misqd_isworld/ interp.htm

11. Ewusi-Mensah, K. and Z.H. Przasnyski, 1994. Factors contributing to the abandonment of information systems development projects. J. Inform. Technol., 9: 185-201. http://doi.acm.org/ $10.1145 / 260750.260775$

12. Gell-Mann M., 1995. What is Complexity? Complexity1:16-19. http://www.santafe.edu / mgm/complexity.html

13. Covney, P. and R. Highfield, 1995. Frontiers of Complexity. Faber and Faber Ltd. London. pp: $\quad 5-42$ http://www.amazon.com/FrontiersComplexity-Search-Order- Chaotic/dp/0449910814

14. Lewin, R., 1993. Complexity: Life on the Edge of Chaos. Phoneix, London. pp: 10-21. http://www.amazon.com/Complexity-Life-at-EdgeChaos/dp/0226476553

15. Stacey, R.D., D. Griffin and P. Shaw, 2000. Complexity and Management, Routledge,London. pp: 106-126, http://www.ebookmall.com/alphaauthors/Ralph-D-Stacey.htm

16. Kelly, E.M., 2003. Ten Principles of Complexity and Enabling Infrastructures in Complex Systems and Evolutionary Perspectives of Organizations: The Application of Complexity Theory to Organizations, Elsevier, Chapter 2: 23-50. http://www.psych.lse.ac.uk/complexity/Papers/Ch2 final.pdf 
17. Mathews, K., C, White and R. Long, 1999. Why study the complexity sciences in the social sciences. Hum. Relat., 52: 439-462 http://hum. sagepub.com/cgi/content/abstract/52/4/439

18. Benbya, H. and B. Mckelvey, 2006. Towards a complexity theory of information systems development.. Inform. Technol. People, 19: 12-34. http://www.emeraldinsight.com/10.1108/09593840 610649952

19. Dhillon, G. and J. Ward, 2002. Chaos theory as a framework for information systems research. Inform. Resour. Manage. J., 15: 5-13. http://www.isy.vcu.edu/ gdhillon/papers.htm

20. Meso, P. and R. Jain, 2006. Agile software development: Adaptive systems principles and best practices. Inform. Syst. Manage., 23 19-30. doi: $10.1201 / 1078.10580530 / 46108.23 .3 .20060601 / 937$ 04.3

21. Cassidy, A., 1998. A Practical Guide to Information Systems Strategic Planning. CRC Press, pp 1-35 http://portal.acm.org/citation. $\mathrm{cfm} ? \mathrm{id}=521828$

22. Neumann, P.G., 1993. Report of the inquiry into the London ambulance service, February 1993forum on risks to the public in computer and related systems. ACM Committee on Computers and Public Policy, 14 (48) April 7. http://portal.acm.org/citation.cfm?doid=159420.15 5829

23. Bradsher, K., 1991. How AT and $\mathrm{T}$ Accident Snowballed. New York Times, January 14, 1991. http://query.nytimes.com/gst/fullpage.html?res=9D 0CE4D8103BF937A25752C0A967958260

24. Oz, E., 1994. When professional students are lax: The confirm failure and its lessons. Commun. ACM, 37: 29-43. [doi $>10.1145 / 194313.194319]$

25. Baranger, M., C. Chaos, 2001. Entropy. A physics talk for non-physicists. http://necsi.org/projects/baranger/cce.pdf.

26. Axelrod, R.M. and M.D. Cohen, 1999. Harnessing Complexity: Organizational Implications of a Scientific Frontier. Free Press, New York, 1-31. http://ebooks.ebookmall.com/ebook/116083ebook.htm
27. Pascale, R.T., M. Millemann and L. Gioja, 2000. Surfing the Edge of Chaos. Crown Business, New York, USA. pp: 113-147. http://www. shearonforschools.com/surfing_the_edge_of_chaos .htm

28. Levy, D., 1994. Chaos theory and strategy: Theory, application and managerial implications. Strategic Manage. J., 15: 167-168. http://docs.thinkfree. com/tools/doc_location.php?ext=pdf\&dsn $=526537$

29. Maxfield, R and D. Lane, 1996. Strategy under complexity: Fostering generative relationships. Long Range Plann., 29: 215-231. doi: 10.1016/0024-6301(96)00011-8

30. Beinhocker, E.D., 1999. Robust adaptive strategies. Sloan Manage. Rev., 40: 95-106. http:// sloanreview.mit.edu/smr/issue/1999/spring/9/

31. Moody, G., 1998. The wild bunch. New Scientist, 160: $\quad 42-46 . \quad$ http://www.newscientist. com/article/mg16021645.400-the-wild-bunch.html

32. Phelan, S., 1995. From Chaos to Complexity in Strategic Planning. Paper presented at the 55th Annual Meeting of the Academy of Management, Vancouver, BC, 1995. http://bus.hanyang.ac. $\mathrm{kr} /$ dynamics/cyber/Useful/use1/22.htm

33. Waldrop, M.M., 1992. Complexity: The Emerging Science at the Edge of Order and Chaos. Viking, London, 10.1002/bs.3830390106

34. Moore, J.F., 1993. Predators and prey: A new ecology of competition. Harvard Business Rev., 75-86

http://harvardbusinessonline.hbsp.harvard .edu/hbsp/hbr/articles/article.jsp?articleID $=93309 \&$ ml_action=get-article\&print $=$ true

35. Tushman, M.L. and P. Anderson, 1986. Technological discontinuities and organizational environments. Administrative Sci. Q., 31: 439-465. http://dx.doi.org/10.2307/2392832 